DOI

\title{
ВОЗРАСТНАЯ СТРУКТУРА, НОЗОЛОГИЧЕСКИЕ ФОРМЫ, СОПУТСТВУЮЩИЕ ЗАБОЛЕВАНИЯ ГОСПИТАЛИЗИРОВАННЫХ ПАЦИЕНТОВ ТЕРАПЕВТИЧЕСКОГО ОТДЕЛЕНИЯ СТАЦИОНАРА ЭКСТРЕННОЙ МЕДИЦИНСКОЙ ПОМОЩИ
}

\author{
ФГ. А. Ахмедова, Г. Р. Шодиева, Ш. Х. Зиядуллаев \\ Самаркандский государственный медицинский институт, узбекистан
}

РЕзюмЕ. Представлены результаты анализа возрастной структуры, нозологических форм, сопутствующих заболеваний пациентов, госпитализированных в отделение экстренной терапии Самаркандского филиала Республиканского научного центра экстренной медицинской помощи. Анализ возрастного состава госпитализированных пациентов свидетельствует о том, что основное место занимает госпитализация лиц пожилого и старческого возраста, и значимое место в данном возрасте отводится на хроническую патологию органов сердечно-сосудистой системы. Серьезное место также занимают острые воспалительные процессы дыхательных путей, возможно, отражающие иммунологическое «неблагополучие» в популяции лиц старшего возраста.

КЛЮчЕВЫЕ СЛОВА: стационар; терапевтическое отделение; госпитализация.

Вступление. Заболевания внутренних органов, как с острым течением, так и с обострением длительно существовавших хронических процессов, требуют неотложной медицинской помощи. Следовательно, в структуре стационаров неотложной медицинской помощи особое значение придается функционированию отделений соматической реанимации, экстренной терапии и неврологии. Неотложные состояния в клинике внутренних болезней нередко связаны с острыми воспалительными процессами дыхательных путей, поражениями оболочек сердца, почечной ткани, а также острыми аллергическими реакциями $[1,5]$. Хроническими болезнями, по данным некоторых проведенных исследований, страдают более 70 \% госпитализированных в терапевтические отделения пациентов [3]. Особое место среди множества неотложных состояний, ассоциированных с обострением хронической патологии, занимают нестабильные варианты стенокардии и острый инфаркт миокарда, развивающиеся вследствие относительной или абсолютной недостаточности коронарного кровообращения, декомпенсация хронической сердечной недостаточности, аритмии, осложненные гипертонические кризы, хронические воспалительные заболевания респираторной системы с дыхательной недостаточностью, астматический статус, хронические диффузные заболевания печени и их осложнения, аутоиммунные, тиреотоксические кризы и пр. [1, 2]. Следует также отметить, что в структуре современного населения многих стран количество людей пожилого и старческого возраста неуклонно растет. Рост продолжительности жизни, в свою очередь, ассоциируется с развитием таких патологических состояний сердечно-сосудистой системы как атеросклероз и ишемическая болезнь сердца, гипертоническая болезнь, инфаркты и инсульты, хронических болезней органов дыхания, онкологических заболеваний, заболеваний опорно-двигательного аппарата и пр. $[1,4]$. У лиц пожилого и старческого возраста одна болезнь может осложняться сопутствующими заболеваниями, а течение многих заболеваний имеет свои характерные особенности.

Целью настоящего исследования стало изучение возрастной структуры, нозологических форм, сопутствующих заболеваний у пациентов, госпитализированных в отделение экстренной терапии СФ РНЦЭМП.

Материал и методы исследования. Ретроспективный анализ проводили по данным отделения экстренной терапии СФ РНЦЭМП за первые 5 месяцев 2016 года. За этот период были изучены 989 медицинских карт стационарного больного. Распределение больных проведено согласно классификации возрастных периодов взрослого человека: 16-25 лет - юноши, 25-40 лет - взрослые, 40-60 лет - зрелые, 60-75 лет пожилые, 76-90 лет - старики и старше 90 лет долгожители. В 1 возрастную группу вошли 35 человек (3,5 \%), во 2 - 85 (8,6 \%), в 3 - $370(37,4 \%)$, в $4-390(39,5 \%)$, в $5-103(10,4 \%)$ и в $6-6(0,6 \%)$. Верификация диагнозов проводилась согласно требованиям МКБ-10 и рабочих классификаций. Проанализированы абсолютные и относительные показатели возрастной структуры, нозологических форм, сопутствующих заболеваний пациентов, госпитализированных в отделение экстренной терапии СФ РНЦЭМП. Статистическая обработка данных проведена с помощью методов описательной статистики. 
Огляди літератури, оригінальні дослідження, погляд на проблему

Результаты и обсуждение. Среди госпитализированных в стационар за анализируемый период больных мужчин было значительно меньше, чем женщин: 219 человека (44,7\%). В 1 группе женщины составили $57 \%$, во 2 - 53 \%, в $3-51 \%$, в 4-54 \%, в $5-58,2 \%$, в 6 (долгожители) - $67 \%$ (4 женщины и 2 мужчин). Эти цифры позволяют сделать заключение о более высокой частоте госпитализаций в терапевтический стационар неотложной помощи среди женщин всех возрастных групп. За проанализированный 5-месячный период пролечено 490 пациентов в возрасте до 60 лет и 499 лиц пожилого и старческого возраста. Большая часть пациентов в возрасте более 60 лет представлена возрастной группой 60-75 лет. Возрастную группу 75-90 лет составили 21 \% пациентов. Возрастную группу долгожителей составило незначительное число пациентов.

Анализ госпитализированных пациентов в I неотложное терапевтическое отделение СФ РНЦЭМП, представленный в таблице, свидетельствует о том, что почти за полугодовой период патология органов сердечно-сосудистой системы заняла первую позицию (694 случая госпитализации, $70,1 \%)$, затем следовали заболевания органов дыхания (199 случаев госпитализации, $20,1 \%)$, далее фигурировали заболевания органов пищеварения (40 случаев госпитализации, $4 \%$ ), эндокринная патология (39 случаев госпитализации, 4 \%), аутоиммунные и другие редкие за- болевания (17 случаев госпитализации, 1,7 \%). Среди диагностированных в стационаре нозологических форм преобладала ИБС в виде стабильной, не уточненной и различных проявлений нестабильной стенокардий (451 пациент, 46 \%), трансформация острого коронарного синдрома в острый инфаркт миокарда наблюдалась у 68 госпитализированных пациентов, далее следовали лица с гипертонической болезнью (199 человек, 20,1\%), осложненными гипертоническими кризами - 134 пациента, и 4 случая госпитализаций с симптоматической гипертонией, пневмония диагностирована у 143 (14,4 \%), с тяжелым течением - у 78 пациентов, хроническая обструктивная болезнь легких у 36 (3,6 \%), бронхиальная астма у $17(1,7 \%)$, цирроз печени у 40 (4\%), сахарный диабет у 39 (4 \%), острая ревматическая лихорадка у $3(0,3 \%)$, хроническая ревматическая болезнь сердца у 37 (3,7 \%), дилатационная кардиомипатия у 4 (0,4 \%). Среди больных хронической обструктивной болезнью легких и бронхиальной астмой лечение в экстренном терапевтическом отделении стационара В основном проходили пациенты с тяжёлой и среднетяжёлой формами обострения болезни.

Большинство госпитализированных пациентов имели сочетанную патологию. В течение анализируемого 5-месячного периода были госпитализированы 601 (61,4 \%) человек, которые имели либо фоновое, либо конкурирующее или сочетанное заболевание в составе комбиниро-

Таблица. Структура нозологических форм госпитализированных в экстренное терапевтическое отделение СФ РНЦЭМП

\begin{tabular}{|l|c|c|}
\hline \multicolumn{1}{|c|}{ Характер патологии (болезни) } & A6c. & $\%$ \\
\hline \multicolumn{1}{|c|}{1} & 2 & 3 \\
\hline Болезни сердечно-сосудистой системы & 694 & 70,1 \\
\hline ИБС & 68 & 9,8 \\
Острый ИМ стабильная стенокардия & 107 & 15,4 \\
Нестбильная стенокардия & 276 & 39,8 \\
\hline ГБ & 199 & 28,6 \\
ГКнеосложненный & 65 & 9,3 \\
ГК осложненный & 134 & 19,4 \\
\hline ХСН & 421 & 42,5 \\
I & 75 & 17,8 \\
II & 281 & 66,7 \\
III & 65 & 15,5 \\
\hline Нарушение ритма и проводимости & 187 & 18,9 \\
\hline ХРБС & 37 & 5,3 \\
\hline ДКМП & 4 & 0,6 \\
\hline ОРЛ & 3 & 0,4 \\
\hline \multicolumn{3}{|c|}{} \\
\hline Пневмония & 143 & 14,5 \\
Среднетяжелое течение & 108 & 75,5 \\
Тяжелое течение & 35 & 24,5 \\
\hline
\end{tabular}




\begin{tabular}{|c|c|c|}
\hline 1 & 2 & 3 \\
\hline $\begin{array}{l}\text { Бронхиальная астма } \\
\text { Среднетяжелое персистирующее течение } \\
\text { Тяжелое персистирующее течение }\end{array}$ & $\begin{array}{c}17 \\
7 \\
10\end{array}$ & $\begin{array}{l}1,7 \\
41 \\
59\end{array}$ \\
\hline $\begin{array}{l}\text { ХОБЛ } \\
\text { Среднетяжелое течение } \\
\text { Тяжелое течение }\end{array}$ & $\begin{array}{l}36 \\
15 \\
21\end{array}$ & $\begin{array}{l}3,6 \\
41,6 \\
58,4\end{array}$ \\
\hline \multicolumn{3}{|l|}{ Болезни желудочно-кишечного тракта } \\
\hline $\begin{array}{l}\text { Цирроз печени } \\
\text { Компенсация } \\
\text { Декомпенсация }\end{array}$ & $\begin{array}{l}40 \\
17 \\
23\end{array}$ & $\begin{array}{c}4 \\
32,5 \\
67,5\end{array}$ \\
\hline Хроническая язва желудка и двенадцатиперстной кишки. & 5 & 0,5 \\
\hline Хронический гастрит & 7 & 0,7 \\
\hline Хронический панкреатит & 6 & 0,6 \\
\hline Хронический холецистит & 11 & 1,1 \\
\hline \multicolumn{3}{|l|}{ Эндокринные болезни } \\
\hline $\begin{array}{l}\text { Сахарный диабет } \\
\text { І тип } \\
\text { II тип }\end{array}$ & $\begin{array}{l}39 \\
18 \\
21\end{array}$ & $\begin{array}{r}3,9 \\
46,1 \\
53,9\end{array}$ \\
\hline Диффузный токсический зоб & 5 & 0,5 \\
\hline
\end{tabular}

ванного основного заболевания, что существенно влияло на ухудшение течения основного заболевания. Так, в течение анализируемого периода, больные имели ишемическую болезнь сердца, гипертоническую болезнь, аритмии и хроническую сердечную недостаточность, а также ХОБЛ или БА, аритмии и хроническое легочное сердце, пневмонию и др. одновременно. В 421 (42,5 \%) случае у пациентов определялись признаки хронической сердечной недостаточности, ХСН I стадии у 75, ХСН ІІА и ІІБ стадий у 281, а ХСН III стадии у 65 госпитализированных. XCH ишемического генеза наблюдалась в 306 случаях. Нарушение сердечного ритма и прово-

\section{ЛИТЕРАТУРА}

1. Денисова Е. В. Актуальные вопросы эпидемиологии сосудистых заболеваний головного мозга в мире / Е. В. Денисова // Вестник общественного здоровья и здравоохранения Дальнего Востока России. - 2011. - № 3. - С. 1-5.

2. Рекомендации Российской гастроэнтерологической ассоциации по диагностике и лечению функциональной диспепсии // Российский журнал гастроэнтерологии, гепатологии, колопроктологии. 2012. - T. 12, № 3. - С. 1-13. димости зарегистрировано у 187 госпитализированных пациентов.

Выводы. Полученные результаты о возрастной структуре и нозологических формах госпитализируемых в терапевтический стационар неотложной помощи свидетельствует, что основное место занимает госпитализация лиц пожилого и старческого возраста, и значимое место в данном возрасте отводится хронической патологии органов сердечно-сосудистой системы. Серьезное место также занимают острые воспалительные процессы дыхательных путей, возможно, отражающие иммунологическое неблагополучие в популяции лиц старшего возраста.

3. Федеральные клинические рекомендации по диагностике и лечению хронической обструктивной болезни лёгких / А. Г. Чучалин, С. Н. Авдеев, 3. Р. Айсанов [и др.] // Пульмонология. - 2014. - № (3). - С. 15-54.

4. Федеральные клинические рекомендации по диагностике и лечению бронхиальной астмы / под ред. А. Г. Чучалина, 2016. -55 с.

5. Distinct clinical phenotypes of airways disease defined by cluster analysis // M. Weatherall, J. Travers, P. M. Shirtcliffe [et al.] // Eur. Respir. J. - 2009. - № 34. - P. 812-818. 
Огляди літератури, оригінальні дослідження, погляд на проблему

\section{REFERENCES}

1. Denisova, E.V. (2011). Aktualnyye voprosy epidemiologii sosudistykh zabolevaniy golovnogo mozga v mire [Topical issues of the epidemiology of cerebrovascular diseases in the world]. Vestnik obshchetvinogo zdorovya $i$ zdravokhraneniya Dalnogo Vostoka Rosii - Journal of Public Health and Public Health of the Far East of Russia, 3, 1-5 [in Russian].

2. (2012). Rekomendatsii Rossiyskoyi gastroenterologicheskoyi assotsiatsii po dia-gnostike i lecheniyu funktsionalnoy dispepsii [Recommendations of the Russian Gastroenterological Association for Diagnosis and Treatment of Functional Dyspepsia]. Rosiyskiy zhurnal gastroenterologii, gepatologii, coloproktologii - Russian Journal of Gastroenterology, Hepatology, Coloproctology, 12 (3), 1-13 [in Russian].
3. Chuchalin, A.G., Avdeev, S.N., \& Aisanov, Z.R. (2014). Federalnyye klinicheskiye rekomendatsii po diagnostike i lecheniyu khronicheskoy obstruktivnoy bolezni logkikh [Federal clinical guidelines for the diagnosis and treatment of chronic obstructive pulmonary disease]. Pulmonologiya - Pulmonology, 3, 15-54 [in Russian].

4. Chuchalina, A.G. (Eds.) (2016). Federalnyye klinicheskiye rekomendatsii po diagnostike $i$ lecheniyu bronkhialnoy astmy [Federal clinical guidelines for the diagnosis and treatment of bronchial asthma] [in Russian].

5. Weatherall, M., Travers, J., \& Shirtcliffe, P.M. (2009). Distinct clinical phenotypes of airways disease defined by cluster analysis. Eur. Respir. J., 34, 812-818.

\title{
ВІКОВА СТРУКТУРА, НОЗОЛОГІЧНІ ФОРМИ, СУПУТНІ ЗАХВОРЮВАННЯ ГОСПІТАЛІЗОВАНИХ ПАЦІЄНТІВ ТЕРАПЕВТИЧНОГО ВІДДІЛЕННЯ СТАЦІОНАРУ ЕКСТРЕНОї МЕДИЧНОЇ ДОПОМОГИ
}

СГ. А. Ахмедова, Г. Р. Шодієва, Ш. Х. Зиядуллаев

Самаркандський державний медичний інститут, узбекистан

РЕЗЮМЕ. Представлені результати аналізу вікової структури, нозологічних форм, супутніх захворювань пацієнтів, госпіталізованих у відділення екстреної терапії Самаркандської філії Республіканського наукового центру екстреної медичної допомоги. Аналіз вікового складу госпіталізованих пацієнтів свідчить про те, що основне місце займає госпіталізація осіб похилого та старечого віку, і значуще місце в даному віці відводиться на хронічну патологію органів серцево-судинної системи. Серйозне місце також займають гострі запальні процеси дихальних шляхів, які, можливо, відображають імунологічне неблагополуччя в популяції осіб старшого віку.

КлючОВІ СлОВА: стаціонар; терапевтичне відділення; госпіталізація.

\section{AGE STRUCTURE, NOSOLOGIC FORM, ASSOCIATED DISEASE OF HOSPITAL PATIENTS OF THERAPEUTIC DEPARTMENT OF EMERGENCY MEDICINE}

\author{
@G. A. Akhmedova, G. R. Shodieva, Sh. Kh. Ziyadullaev
}

\section{Samarkand State Medical Institute, Uzbekistan}

SUMMARY. The article adduces the results of the analysis of the age structure, nosologic form, accompanying diseases of patients hospitalized in therapy departments of Samarkand branch of Republican research centre of emergency medicine. An analysis of hospitalized patients suggests that the main place is occupied by person's hospitalized elderly, and a significant place in this age is given to a chronic pathology of the cardiovascular system. Serious place is also occupied by acute inflammation of the airways, possibly reflecting the immunological "trouble" in the population of older persons.

KEY WORDS: hospital; therapy department; hospitalization. 